\title{
Ecoturismo: uma opção de manejo sustentável para o Pantanal?!
}

\section{Wolfgang J. Junk}

Doutor em Zoologia, Botânica, Química, Oceanografia e Limnologia pela Universidade de Kiel (Christian-Albrechts Universität), 1970. Livre-docente em Ecologia Tropical (1990) e pesquisador sênior e líder do Grupo Ecologia Tropical no Instituto Max Planck para Limnologia em Ploen, Alemanha. Coordenador científico do Instituto Nacional em Ciência e Tecnologia em Áreas Úmidas.

\begin{abstract}
Sumário: 1. Introdução. 2. Definição e caracterização hidrológica e ecológica do Pantanal Mato-grossense; 3. Bens e serviços que o Pantanal fornece para o homem; 4. Principais ameaças para a integridade ecológica do Pantanal; 5. Avaliação dos impactos gerais para o ecossistema provenientes dos atores principais que atuam dentro do Pantanal; 6. Recomendações para ações futuras; 7. Conclusão; 8. Referências.
\end{abstract}

\section{Introdução}

O Pantanal Mato-grossense é uma Área Úmida (AU) de destaque nacional e internacional com os títulos de "Patrimônio Nacional" e "Reserva da Biosfera". Além destes, contém dois sítios Ramsar (Parque Nacional do Pantanal e RPPN Sesc Pantanal). O título de Patrimônio da Humanidade foi dado ao Conjunto de RPPNs Ecotrópica e Parque Nacional.

Em 1993, o Brasil assinou a Convenção de Ramsar, promulgada pelo Decreto ${ }^{\circ}$ 1.905, de 16 de maio de 1996. Esta convenção pressupõe uma política nacional para a gestão inteligente (wise management) e a proteção das AUs e sua biodiversidade.

Muitas exigências desta convenção ainda não foram atendidas pelo governo brasileiro, entre elas, a elaboração e implementação de um plano de manejo sustentável, que garanta a integridade estrutural e funcional deste ecossistema complexo. Isso levou o Pantanal ao ponto de arriscar a perder o título de "Reserva da Biosfera".

1 Artigo elaborado com base em palestra proferida pelo autor no dia 20 de abril de 2017 , na terceira reunião do Fórum Regional de Desenvolvimento do Turismo Sustentável: Pantanal, Amazônia e Cerrado (FIT). 
No Pantanal Mato-grossense existem diferentes abordagens de manejo, principalmente quanto à pecuária tradicional, pecuária intensiva, pesca profissional, pesca esportiva e ecoturismo. Além disso, existem muitas ameaças, tais como a construção da hidrovia Paraguai-Paraná, a poluição pela mineração ao redor do Pantanal, poluição pelos esgotos despejados nos tributários, assoreamento pelo excesso de sedimentos das atividades agropecuárias no Planalto, e transportadas para dentro do Pantanal (a exemplo do que ocorre no Rio Taquari), mudanças do regime hídrico pelas represas e barragens, drenagem de áreas pantanosas, destruição das florestas e de outros macrohabitats, etc.

A questão abordada neste artigo é: Qual é o papel do ecoturismo neste cenário?

\section{Definições e caracterização hidrológica e ecológica do Pantanal Mato-grossense}

Nos últimos anos, um consórcio de cientistas brasileiros ${ }^{2}$ elaborou a seguinte definição de AUs brasileiras:

Áreas Úmidas (AUs) são ecossistemas na interface entre ambientes terrestres e aquáticos, continentais ou costeiros, naturais ou artificiais, permanentemente ou periodicamente inundados por águas rasas ou com solos encharcados, doces, salobras ou salgadas, com comunidades de plantas e animais adaptadas à sua dinâmica hídrica.

De acordo com esta definição, o Pantanal Mato-grossense é uma AU periodicamente inundada.

Os mesmos autores ${ }^{3}$ definem a extensão de AUs da seguinte forma:

A extensão de uma AU é determinada pelo limite da inundação rasa ou do encharcamento permanente ou periódico, ou no caso de áreas sujeitas aos pulsos de inundação, pelo limite da influência das inundações médias máximas, incluindo-se aí, se existentes, áreas permanentemente secas em seu interior, habitats vitais para a manutenção da

\footnotetext{
2 JUNK, W. J.; PIEDADE, M. T. F.; LOURIVAL, R.; WITTMANN, F.; KANDUS, P.; LACERDA, L. D.; BOZELLI, R. L.; ESTEVES, F. A.; NUNES DA CUNHA, C.; MALTCHIK, L.; SCHOENGART, J.; SCHAEFFER-NOVELLI, Y.; AGOSTINHO, A. A.; NÓBREGA, R. L. B. Parte I: Definição e Classificação das Áreas Úmidas (AUs). Brasileiras: Base Científica para uma Nova Política de Proteção e Manejo Sustentável. In: NUNES DA CUNHA, C; PIEDADE, M. T. F.; JUNK, W. J. (Orgs.). Classificação e Delineamento das Áreas Úmidas Brasileiras e de seus Macrobabitats. Cuiabá-MT: EdUFMT, 2014b. p. 13-76.

3 Idem.
} 
integridade funcional e da biodiversidade das mesmas. Os limites externos são indicados pelo solo hidromórfico, e/ou pela presença permanente ou periódica de hidrófitas e/ou de espécies lenhosas adaptadas a solos periodicamente encharcados.

Esta definição contém dois aspectos-chaves inovadores: o primeiro aspecto inovador é a referência ao nível médio máximo da inundação como limite externo das AUs. Esta visão está de acordo com a definição do antigo código florestal (Lei 4771, de 1965), mas foi contraditada pelo atual código florestal (Lei 12.651, de 2012), que define a regulamentação das Áreas de Proteção Permanente (APPs) a partir do nível regular, onde a água do rio normalmente corre, deixando portanto parte das AUs e seus recursos hídricos sem proteção nenhuma.

Adotado o delineamento das AUs apresentado por Junk et al. ${ }^{4}$, o Brasil iria diminuir consideravelmente os riscos de catástrofes econômicas e sociais durante inundações e secas extremas, causadas pelo uso inapropriado das AUs, não respeitando os seus limites determinados pelas inundações médias máximos, que não ocorrem a cada ano, mas em períodos imprevisíveis multianuais.

Do ponto de vista ecológico, inundações e secas extremas têm grande importância para o reajustamento da vegetação do Pantanal, o que torna o sistema muito dinâmico. De acordo com as previsões do Painel do Clima Global, estas situações extremas vão ocorrer no futuro mais frequentemente por causa das mudanças climáticas a serem esperadas.

O segundo aspecto refere-se à inclusão de áreas permanentemente secas dentro das AUs, levando em consideração a sua importância para a manutenção da biodiversidade. A evolução da biodiversidade do Pantanal está intimamente ligada a estes macrohabitats. Muitos animais usam estas áreas representadas pelos capões, cordilheiras, leques aluviais e inselberges como refúgios periódicos durante as enchentes e podem migrar lateralmente durante os períodos de cheia e seca em busca de recursos e proteção.

Inundações e secas periódicas, chamadas também de "pulso de inundação", caracterizam a grande maioria das AUs brasileiras. O pulso de inundação é o fator principal, que determina as condições ecológicas nestes sistemas. Existem diferentes tipos de pulso de inundação. O Pantanal pertence ao

4 JUNK, W. J.; PIEDADE, M. T .F.; LOURIVAL, R.; WITTMANN, F.; KANDUS, P.; LACERDA, L. D.; BOZELLI, R. L.; ESTEVES, F. A.; NUNES DA CUNHA, C.; MALTCHIK, L.; SCHÖNGART, J.; SCHAEFFER-NOVELLI, Y.; AGOSTINHO, A. A. Brazilian wetlands: their definition, delineation, and classification for research, sustainable management, and protection. Aquatic Conservation: Marine and Freshwater Ecosystems, 24 (1), p. 5-22, $2014 \mathrm{a}$. 
grupo de AUs sujeito a um pulso monomodal (uma enchente e uma seca por ano), previsível e de baixa amplitude (na maioria dos casos até $2 \mathrm{~m}$ de inundação), (gráfico 1).

As estruturas, os processos e a biodiversidade em AUs sujeitas a pulsos de inundação são descritos pelo "Conceito de Pulso de Inundação"s. Este conceito trata as fases aquáticas e terrestres na "Zona de Transição Aquática Terrestre (ATTZ)" como estágios diferentes do mesmo ecossistema, que se influenciam reciprocamente, e são a base para suas características específicas. Mudanças do pulso de inundação têm sérios impactos nas características destes ecossistemas.

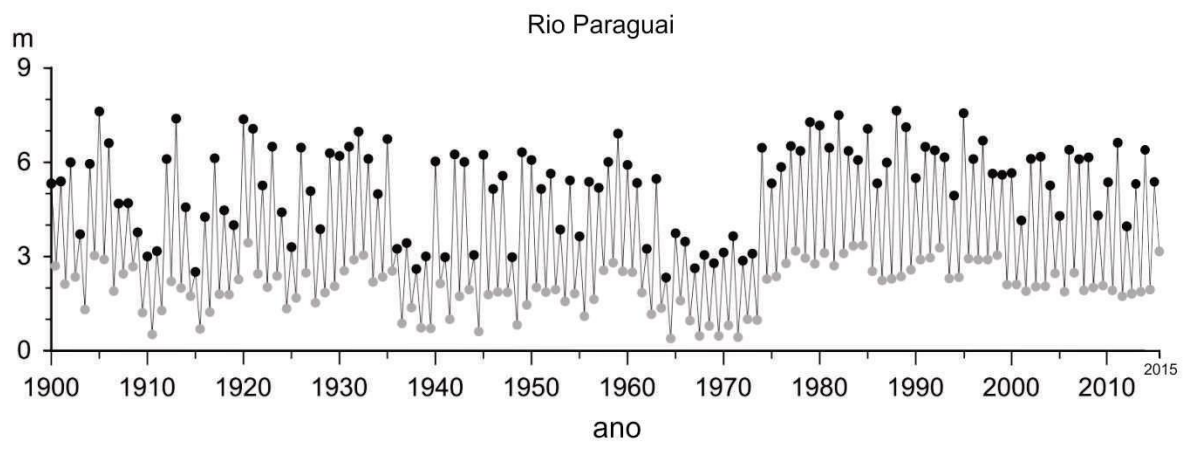

Gráfico 1 - Flutuação de nível de água do Rio Paraguai (pulso de inundação) em Ladário Fonte: Departamento Nacional de Águas e Energia Elétrica (DNAEE)

Grandes áreas úmidas são ecossistemas muito complexos, com um grande número de diferentes unidades de paisagem. Para sua caracterização ecológica e para fins de manejo sustentável, os cientistas diferenciaram as grandes AUs em unidades funcionais. "Unidade funcional é uma macrorregião, mostrando condições hidrológicas similares". Eles estabeleceram cinco unidades funcionais naturais de acordo com o seu estágio hidrológico (figura 1) e uma sexta unidade representando áreas fortemente modificadas pelo homem, sem diferenciá-la em respeito às condições hidrológicas.

5 JUNK, W. J.; BAYLEY, P. B.; SPARKS, R. E. The flood pulse concept in river floodplain systems. Canadian Journal of Fishers and Aquatic, 106, p. 110- 127, 1989. 


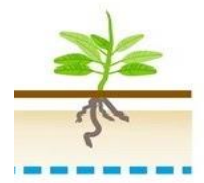

Un. Func. Permanentemente

Terrestre

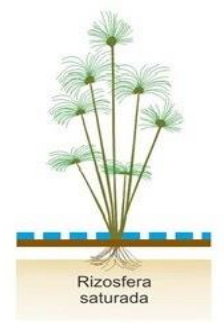

Un. Func. Pantanosa

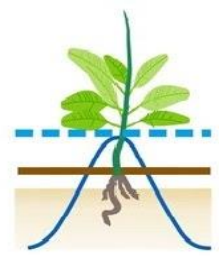

Un. Func. Predominantemente Terrestre
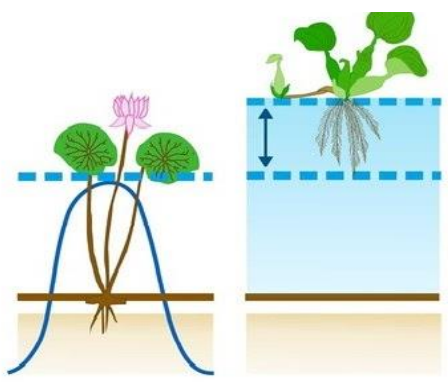

Un. Func. Predominantemente Aquática
Un. Func. Permanentemente Aquática

$\begin{array}{ll} & \text { Rizosfera } \\ & \text { Superficie do solo } \\ = & \text { Nivel da água } \\ \text { Zona de saturação ou flutuação periódica do nivel d'água } & \end{array}$

Figura 1 - As 5 unidades funcionais naturais no Pantanal Mato-grossense: (1) Áreas permanentemente aquáticas, (2) áreas pantanosas, permanentemente encharcadas e/ou inundadas por água rasa, (ATTZ), (3) áreas predominantemente terrestres, (ATTZ), (4) áreas predominantemente aquáticas, (ATTZ), (5) Áreas permanentemente terrestres

Fonte: Nunes da Cunha \& Junk 2017, modificado.

Estas unidades funcionais foram subdivididas em unidades menores chamadas macrohabitats. "Macrohabitat é uma área grande sujeita às mesmas condições hidrológicas e coberta por uma vegetação característica”. Até agora foram descritas para o Pantanal Mato-grossense 57 diferentes macrohabitats ${ }^{6}$, mas este número ainda irá aumentar, quando novos macrohabitats de Mato Grosso do Sul forem incluídos.

\section{Bens e serviços que o Pantanal fornece para o homem}

Os bens e serviços que um ecossistema fornece para o homem podem ser descritos como "Capital Natural".

Ecossistemas são capital renovável. Este capital pode ser coletado, rendendo bens ecossistêmicos (tais como madeira), mas eles podem também render um fluxo de serviços ecossistêmicos, quando deixado no lugar (tais como controle de erosão ou recreação). ${ }^{7}$

6 NUNES DA CUNHA, C.; JUNK, W. J. Classificação dos Macrohabitats do Pantanal Mato-grossense. In: NUNES DA CUNHA, C; PIEDADE, M. T. F.; JUNK, W. J. (Orgs.). Classificação e Delineamento das Áreas Úmidas Brasileiras e de seus Macrohabitats. Cuiabá-MT: EdUFMT, 2014. p. 77-122.

7 COSTANZA, R.; DALY, H. E. Natural capital and sustainable development. Conservation Biology, 6 (1), p. 37-46, 1992. 
Uma primeira avaliação dos valores médios econômicos de recursos naturais, serviços ambientais, biodiversidade e valores culturais de ecossistemas foi oferecida por Costanza et al. (1997) ${ }^{8}$. Rios e áreas úmidas: 8.498 US $\$$ ha $^{-1}$ ano $^{-1}$, florestas: 969 US $\$$ ha $^{-1}$ ano $^{-1}$, savanas: 232 US $\$$ ha $^{-1}$ ano $^{-1}$. Uma análise mais recente ${ }^{9}$ chegou para AUs interiores a um valor ainda mais alto de 25,682 US $\$$ ha $^{-1}$ ano $^{-1}$. Naturalmente, os valores diferem entre as regiões. Um cálculo de Seidl e Moraes (2000) ${ }^{10}$ usando a mesma abordagem de Costanza et al. (1997) ${ }^{11}$ para o Pantanal de Nhecolândia resultou em cerca da metade do valor das AUs mundiais. Mesmo assim, o valor é impressionante.

Entretanto, os bens e serviços ecossistêmicos têm que ser divididos em bens comerciais, quer dizer, em bens que criam diretamente recursos financeiros para o dono, por exemplo, produção de carne bovina, madeira ou pescado, e em serviços não comerciais, que a sociedade aproveita sem pagar por eles, por exemplo, beleza paisagística, água limpa e pastagens nativas.

Por serem recursos de livre acesso, por cuja exploração os usuários não pagam nada, muitos membros da sociedade tendem a superexplorar e destruir estes recursos comuns, satisfazendo os seus interesses individuais e comprometendo com isso os interesses da sociedade inteira (HARDIN, 1968) ${ }^{12}$. A maioria dos serviços ambientais do Pantanal são não comerciais, como mostrado na tabela 1 .

8 COSTANZA, R.; D’ARGE, R.; DE GROOT, R.; FARBER, S.; GRASSO, M.; HANNON, B.; LIMBURG, K.; NACEM, S.; O'NEILL, R. V.; PARNEL, J.; RASKIN, R. G.; SUTHON, P.; VAN DEN BELT, M. The value of the world's ecosystem services and natural capital. Nature 387, p. 253-260, 1997.

9 DE GROOT, R.; BRANDER, L; PLOEG, S.; COSTANZA, R. et al. Global estimates of the value of ecosystems and their services in monetary units. Ecosystem Services, 1, p. 50-61, 2012.

10 SEIDL, A.; MORAES, A. Global valuation of ecosystem services: application to the Pantanal da Nhecolandia, Brazil. Ecological Economics, 33 (1), p. 1-6, 2000.

11 COSTANZA, R.; D’ARGE, R.; DE GROOT, R.; FARBER, S.; GRASSO, M.; HANNON, B.; LIMBURG, K.; NACEM, S.; O’NEILL, R. V.; PARNEL, J.; RASKIN, R. G.; SUTHON, P.; VAN DEN BELT, M. The value of the world's ecosystem services and natural capital. Nature 387, p. 253-260, 1997.

12 HARDIN, Garrett. The tragedy of the commons. Science 162, n. 3859, p. 1243-1248, 1968. 


\begin{tabular}{clc}
\hline No & Bens e serviços & Classificação \\
\hline 1 & Moradia para populações tradicionais & $\mathrm{C}$ \\
2 & Pecuária & $\mathrm{C}$ \\
3 & Pesca & $\mathrm{C}$ \\
4 & Ecoturismo & $\mathrm{C}$ \\
& Fornecimento de produtos madeireiros e não & \\
5 & madeireiros (fibras, pastagens nativas, plantas & \\
& medicinais, frutas, etc. & $\mathrm{NC}$ \\
6 & $\begin{array}{l}\text { Estocagem periódica da água e a sua lenta devolução } \\
\text { para os córregos e rios conectados, reduzindo com }\end{array}$ & \\
7 & $\begin{array}{l}\text { isso as flutuações do nível da água e o perigo de } \\
8\end{array}$ & Recarga dos aquíferos e do lençol freático \\
9 & Retenção de sedimentos & $\mathrm{NC}$ \\
10 & Fornecimento de água limpa & $\mathrm{NC}$ \\
11 & Regulação do microclima & $\mathrm{NC}$ \\
12 & Recreação (banho, pesca, lazer) & $\mathrm{NC}$ \\
13 & Manutenção da biodiversidade & $\mathrm{NC}$ \\
14 & Estocagem de carbono orgânico & $\mathrm{NC}$ \\
15 & Manutenção de valores culturais (e.g. música, arte, & $\mathrm{NC}$ \\
\hline
\end{tabular}

Tabela 1 - Bens e serviços comerciais (C) e não comerciais (NC) do Pantanal

\section{Principais ameaças para a integridade ecológica do Pantanal}

As ameaças para a integridade ecológica do Pantanal podem ser diferenciadas em ameaças internas, provenientes de atividades humanas dentro da área e ameaças externas, que ocorrem fora do Pantanal. As ameaças incluem atividades que afetam o ecossistema diretamente, tal como destruição ambiental, e indiretamente, tais como falta de uma legislação adequada ou pressões econômicas, e.g. para aumentar a produção de carne bovina por unidade de área, para competir com as fazendas no cerrado, ou para a construção da hidrovia Paraguai-Paraná, que, em primeira linha, satisfaz o interesse do agronegócio na bacia do Alto Paraguai de ter uma via de transporte barata para seus produtos.

O quadro 1 apresenta as principais ameaças. Porém, há que se destacar que esta lista não é completa e, além disso, novas ameaças podem surgir no futuro. 


\section{Ameaças Internas}

(1) Destruição de macrohabitats essenciais, por exemplo o desmatamento de capões e cordilheiras e outras áreas florestadas, drenagem de áreas pantanosas;

(2) Modificação da hidrologia, por exemplo, pela construção de estradas sem passagem para o fluxo de água;

(3) Exploração indevida dos recursos naturais (pesqueiros, madeireiros e não madeireiros, e da biodiversidade);

(4) Introdução descontrolada de organismos de outros ecossistemas, a exemplo do tucunaré, do búfalo e do javali;

(5) Poluição genética, e.g., pela produção descontrolada de híbridos de peixes, que podem escapar no meio ambiente;

\section{Ameaças Externas}

(6) Poluição por esgotos e resíduos domésticos dos tributários;

(7) Poluição por resíduos industriais e de mineração;

(8) Aumento da carga sedimentar dos tributários em consequência da erosão acelerada nas áreas agropastoris do planalto, por exemplo, do Rio Taquari;

(9) Construção de hidrelétricas, que modificam o pulso de inundação rio abaixo e interrompem a conectividade ao longo da calha do rio, interferindo, p. ex., com as piracemas;

(10) Construção de hidrovia não adaptada ao leito natural do rio, que modificará o regime hidrológico, para atender interesses econômicas de grupos agindo fora do Pantanal;

(11) Falta de uma legislação específica de proteção e manejo, baseada no conhecimento científico;

(12) Falta de uma estrutura hierárquica clara e coerente dos diferentes órgãos executores para a sua implementação e gestão voltada à sustentabilidade;

(13) Mudanças do clima global.

Quadro 1 - As principais ameaças internas e externas que influenciam a integridade ecológica do Pantanal 


\section{Avaliação dos impactos gerais para o ecossistema provenientes dos atores principais, que atuam dentro do Pantanal}

Existem diferentes grupos de atores dentro do Pantanal. Pretendemos, aqui, considerar somente os principais. Fazendeiros tradicionais e fazendeiros não tradicionais são os atores principais, porque eles são os donos de cerca de $90 \%$ da área do Pantanal. Pescadores profissionais e pescadores "esportistas" atuam somente em alguns macrohabitats permanente ou predominantemente aquáticos. Os empreendedores do ecoturismo normalmente atuam em combinação com fazendas tradicionais. Outros grupos, tais como ribeirinhos, populações tradicionais e povos indígenas não são avaliados aqui porque eles ocupam somente pequenas áreas no Pantanal.

Fazendeiros tradicionais são aqueles que realizam uma pecuária extensiva, mantendo a diversidade dos macrohabitats há séculos. Modificações do meio ambiente restringem-se à limpeza do campo para evitar a perda de pastos naturais por causa da invasão de algumas espécies lenhosas, tais como pombeiro, cambará, lixeira e arrebenta-laço.

O problema econômico deste tipo de manejo é que a produtividade de carne bovina por área (valor comercial) é baixa, porque muitos macrohabitats contribuem pouco para a produção de carne bovina. Na situação econômica atual as fazendas são relativamente pequenas para sustentar o fazendeiro e sua familia. Em compensação, é alta a manutenção dos valores não comerciais deste tipo de manejo.

Fazendeiros não tradicionais são aqueles que querem maximizar a produção de carne bovina, aumentando a área de pasto à custa da destruição da maioria dos macrohabitats, por exemplo, pelo desmatamento de capões e cordilheiras, destruição dos murundus e campos savânicos naturais, e drenagem de pântanos. O resultado é uma paisagem uniformizada de extensas pastagens cobertas com capins exóticos sem diversidade de macrohabitats, que poderiam providenciar valores não comerciais, por exemplo, sem beleza paisagística e uma biodiversidade dramaticamente reduzida.

Economicamente, este modelo é superior em comparação às fazendas tradicionais, por causa da produção mais alta da carne por unidade de área. Mesmo assim, ela não é competitiva com a produção das fazendas do planalto, que não sofrem com o pulso de inundação anual. Além disso, este modelo é vulnerável em uma época de mudança climática global, que prevê enchentes e secas extremas, aumentando os riscos de perdas econômicas severas. 
A seu turno, pescadores profissionais e "esportivos" usam somente poucos macrohabitats, na maioria permanentemente aquáticos, sem destruir sua vegetação e hidrologia. Impactos negativos podem ocorrer pela pesca predatória, que frequentemente é associada com a pesca esportiva e pelos isqueiros que destroem os macrohabitats, nos quais eles coletam as iscas vivas.

Para caracterizar o ecoturismo, baseamo-nos na definição da Sociedade Internacional de Ecoturismo (TIES): "Ecoturismo é uma forma responsável de viajar para regiões naturais, que contribui para a proteção do meio ambiente e para o bem-estar da população local". Isso significa o respeito do turista frente à natureza e à população local, evitando, entre outros, a exploração demasiada dos recursos naturais locais e a poluição ambiental.

O ecoturismo no Pantanal fundamenta-se em três pilares: (1) Beleza paisagística baseada na configuração geomorfológica associada às características da vegetação savânica caracterizada pela grande diversidade de macrohabitats; (2) Grande diversidade e abundância de plantas e animais, que chamam atenção dos visitantes (principalmente mamíferos, pássaros, répteis, anfíbios e peixes, que dependem da manutenção da diversidade dos macrohabitats); (3) Autenticidade cultural, representada principalmente pelas populações tradicionais e os fazendeiros tradicionais. Isso significa que a base dos três pilares do ecoturismo são serviços ecossistêmicos não comerciais.

Minha avaliação simplificada do impacto dos atores baseia-se na seguinte premissa: a grande diversidade de macrohabitats no Pantanal é uma característica inerente deste ecossistema e tem que ser mantida, porque ela garante os múltiplos benefícios comerciais e não comerciais (inclusive a biodiversidade) que o Pantanal oferece para o homem. Qualquer método de manejo que destrói em grande escala esta diversidade tem impacto negativo ao ecossistema.

Um estudo realizado no Pantanal de Poconé ${ }^{13}$ mostra que os fazendeiros tradicionais reconheceram a grande maioria dos macrohabitats estabelecidos pelos cientistas e eram capazes de dar um valor específico para cada um, tanto em respeito ao gado bovino, quanto para a vida silvestre (tabela 2). Quer dizer, os grupos atuando dentro do Pantanal têm que adaptar os métodos de manejo a este ecossistema complexo, em vez de tentar adaptá-lo a métodos

13 DUARTE, T. G.; NUNES DA CUNHA, C.; JUNK, W. J. Reconhecimento e apreciação da classificação dos macrohabitats do Pantanal Mato-grossense por pantaneiros de Poconé - MT. In: NUNES DA CUNHA, C.; ARRUDA, E. C.; JUNK, W. J. (Orgs.). Marcos Referenciais para a Lei Federal do Pantanal e gestão de outras áreas úmidas. Cuiabá-MT: EdUFMT, Carlini \& Caniato, 2017. p. 81-97. 
de manejo simplificados, que são altamente destrutivos. Não existe argumento que justifique a não utilização da classificação dos macrohabitats para fins de manejo e gestão do Pantanal.

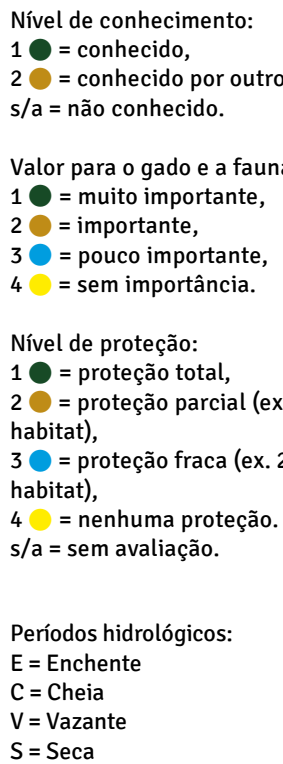

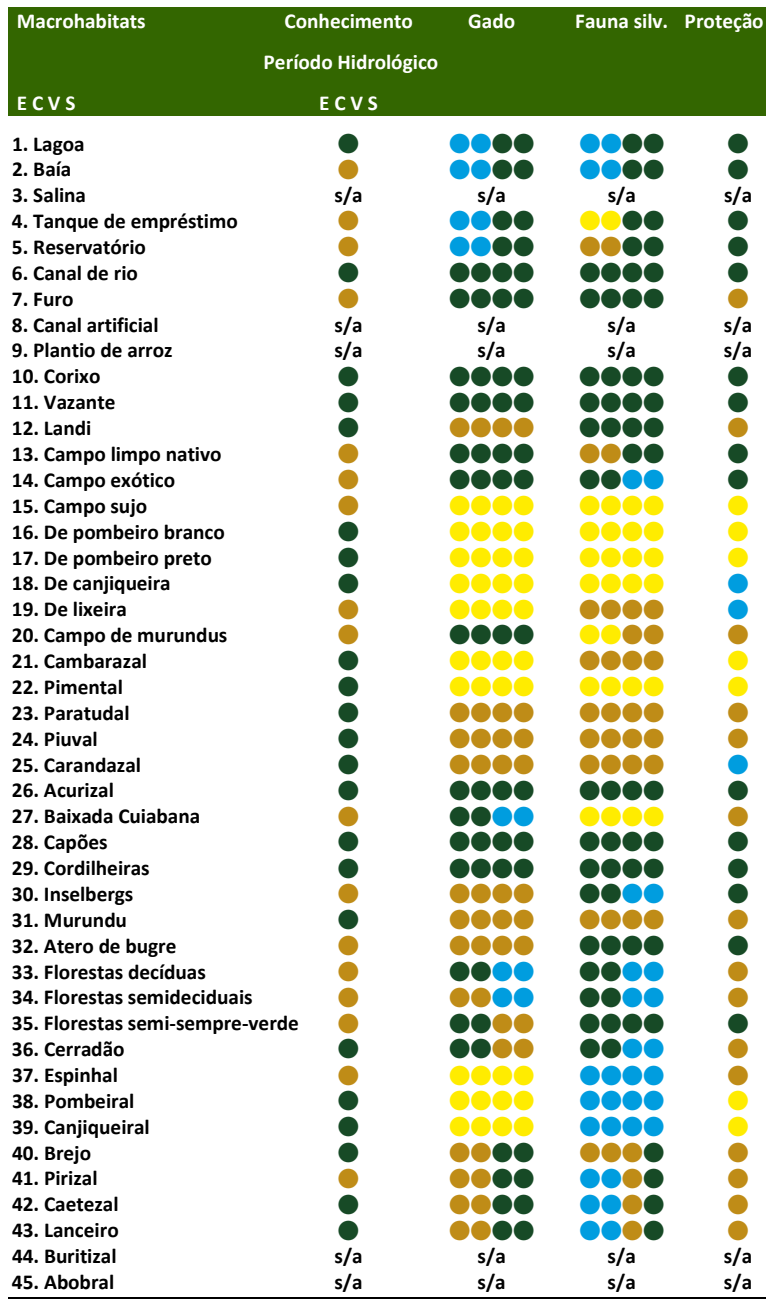

Tabela 2 - Resumo dos resultados dos levantamentos sobre o nível de conhecimento dos pantaneiros dos principais macrohabitats e a sua opinião sobre o seu valor para o gado e a fauna silvestre durante os diferentes períodos hidrológicos

Fonte: Duarte et al., 2017.

Os empreendimentos do ecoturismo são normalmente realizados em consórcio com fazendas tradicionais, porque eles podem aproveitar-se da diversidade dos macrohabitats delas e da disponibilidade das atividades tradicionais culturais, tanto em respeito ao manejo do gado, quanto em respeito às músicas, artes tradicionais e culinária típica. Isso significa um número redu- 
zido de pessoas por fazenda e uma controle do impacto dos turistas ao meio ambiente pelo próprio fazendeiro, porque a atração da fazenda depende do meio ambiente intacto.

O ecoturismo suporta a manutenção da diversidade dos macrohabitats e sua integridade e pode estimular ações locais para aumentar a presença de espécies de interesse turístico. Estas ações podem incluir, por exemplo, o enriquecimento das florestas das fazendas com árvores frutíferas nativas, que ampliam a oferta alimentícia para pássaros e pequenos mamiferos, a escavação de tanques em locais específicos para aumentar a disponibilidade de água para o gado e os animais silvestres durante a seca, a limpeza de tanques de excesso de macrófitas aquáticas, e a ampliação dos locais de nidificação por caixas artificiais, e.g. para a arara-azul.

Entretanto os impactos devem ser monitorados constantemente, introduzindo-se medidas preventivas e corretivas. Por isso, é relevante uma liderança política para a garantia da sustentabilidade. A avaliação generalizada dos impactos dos atores principais encontra-se no quadro 2.

\begin{tabular}{ll}
\hline & Impacto geral \\
\hline Os fazendeiros tradicionais & positivo \\
Os fazendeiros não-tradicionais & negativo \\
Os pescadores profissionais & positivo \\
Os pescadores "esportivos" & em parte negativo por causa da \\
& $\begin{array}{l}\text { pesca predatória e a atuação dos } \\
\text { isqueiros }\end{array}$
\end{tabular}

Os empreendimentos do ecoturismo sustentável (normalmente em consórcio com muito positivo fazendas tradicionais)

Quadro 2 - Avaliação generalizada dos impactos dos atores principais dentro do Pantanal a sua integridade ecológica

Analisando os argumentos apresentados acima, levantam-se duas perguntas:

Pergunta 1: Quem é responsável para manter a integridade ecológica do Pantanal?

Resposta: Cabe à União apresentar lei federal para a gestão do Pantanal, já que se trata de bioma compartilhado entre dois entes da federação: MT e MS. Entretanto, há que se destacar que esse regramento federal trará disposições genéricas, cabendo aos estados apresentar proposições adequadas ao seu território observando as peculiaridades desse bioma em cada estado. 
A responsabilidade dos governos inclui não somente os valores ecossistêmicos comerciais, mas também os valores não comerciais, tais como a providência de água limpa para a população local, que é garantida pela Constituição. A manutenção da biodiversidade foi assumida também pelo governo federal em convenções internacionais.

Realidade: A proposta de uma legislação federal está em pauta, mas deve-se observar que a sua edição não será suficiente para garantir a efetividade da proteção ao meio ambiente, já que caberá aos estados regulamentar os diversos instrumentos criados pela lei federal observando suas peculiaridades.

Ações a serem tomadas: Aperfeiçoar a proposta da lei do Pantanal, apresentar a proposta em audiências públicas, provocar sua difusão nos estados, mobilizar a sociedade para reivindicar a aprovação da norma e, enfim, garantir a sua aplicabilidade, considerando a necessidade de sua ulterior regulamentação pelos estados que compartilham o Pantanal.

Alguns atores da própria comunidade pantaneira, tais como os fazendeiros tradicionais e a maioria dos atores do ecoturismo, assumem atualmente em nível local a responsabilidade do governo de proteger a integridade do ecossistema para o bem da comunidade.

Pergunta 2: Quais são os benefícios que estes atores atualmente recebem para manter os valores não comerciais do Pantanal?

Resposta: Nenhum.

Realidade: Eles só têm prejuízos, mantendo intacta a diversidade dos macrohabitats, em vez de convertê-los em pastagens artificiais de capins exóticos para a produção de gado bovino, como fazem os atores destruidores, tanto de fora, quanto de dentro do Pantanal!

Ações a serem tomadas: Criação de uma proposta interestadual aplicável ao Pantanal de compensação por serviços ambientais, que inclua os valores não comerciais, para cuja manutenção os fazendeiros tradicionais contribuem diretamente. A inclusão destes atores locais na proteção ambiental é (1) mais barata e eficiente que qualquer atividade oficial do Estado; (2) aumenta a aceitação da proteção ambiental pela população pantaneira; e (3) forma uma rede densa de macrohabitats protegidos em fazendas tradicionais no Pantanal inteiro, que pode complementar outras ações de proteção, sejam públicas, tais como parques nacionais e APPs, ou privadas, como RPPNs. 


\section{Recomendações para ações futuras}

Nesse quadro, o setor turístico no Pantanal tem que:

(1) se organizar melhor (resultado da $3^{\underline{a}}$ Reunião do FIT em Cuiabá);

(2) elaborar planos de ação para aumentar a atração das localidades de ecoturismo;

(3) procurar parceiros competentes que podem ajudar na elaboração destes planos e na solução de problemas técnicos;

(4) elaborar propostas de projeto de lei, que beneficiam economicamente as atividades de atores que mantenham os valores não comerciais do Pantanal; (5) cobrar apoio dos políticos dos estados de MT e MS, para a implantação destes regulamentos;

(6) documentar as atividades tomadas para o manejo sustentável dos valores comerciais e não comerciais do Pantanal, e divulgá-las amplamente; (7) abordar com esta documentação organizações nacionais e internacionais para conseguir apoio financeiro e técnico.

\section{Conclusão}

Nosso desafio é conseguir que o conhecimento técnico e cientifico disponível sobre o Pantanal Mato-grossense seja utilizado para a elaboração de uma legislação moderna e justa, que mantenha a diversidade ecológica e cultural da região e que compense economicamente os esforços dos fazendeiros tradicionais em combinação com o ecoturismo na manutenção dos valores não comerciais da região, em benefício de toda a população.

Títulos bonitos, tais como "Patrimônio da Humanidade" e "Reserva da Biosfera", só ajudam se eles vêm com apoio político e financeiro para a população local! Mas este apoio tem que ser ativamente procurado pelos interessados.

\section{Referências}

BRASIL. Lei 4.771, de 15 de setembro de 1965. Institui o novo código florestal. Diário Oficial [da] República Federativa do Brasil, Brasilia, DF, 1965.

. Lei 12.651, de 25 de maio de 2012. Dispõe sobre a proteção da vegetação nativa; e dá outras providências. Diário Oficial [da] República Federativa do Brasil, Brasilia, DF, 2012.

COSTANZA, R.; DALY, H. E. Natural capital and sustainable development. Conservation Biology, 6 (1), p. 37-46, 1992. 
COSTANZA, R.; D’ARGE, R.; DE GROOT, R.; FARBER, S.; GRASSO, M.; HANNON, B.; LIMBURG, K.; NACEM, S.; O'NEILL, R. V.; PARNEL, J.; RASKIN, R. G.; SUTHON, P.; VAN DEN BELT, M. The value of the world's ecosystem services and natural capital. Nature 387, p. 253-260, 1997.

DE GROOT, R.; BRANDER, L; PLOEG, S.; COSTANZA, R. et al. Global estimates of the value of ecosystems and their services in monetary units. Ecosystem Services, 1, p. 50-61, 2012.

DUARTE, T. G.; NUNES DA CUNHA, C.; JUNK, W. J. Reconhecimento e apreciação da classificação dos macrohabitats do Pantanal Mato-grossense por pantaneiros de Poconé - MT. In: NUNES DA CUNHA, C.; ARRUDA, E. C.; JUNK, W. J. (Orgs.). Marcos Referenciais para a Lei Federal do Pantanal e gestão de outras áreas úmidas. Cuiabá-MT: EdUFMT, Carlini \& Caniato, 2017. p. 81-97.

HARDIN, Garrett. The tragedy of the commons. Science 162, n. 3859, p. 1243-1248, 1968.

JUNK, W. J.; BAYLEY, P. B.; SPARKS, R. E. The flood pulse concept in river floodplain systems. Canadian Journal of Fishers and Aquatic, 106, p. 110- 127, 1989.

JUNK, W. J.; PIEDADE, M. T .F.; LOURIVAL, R.; WITTMANN, F.; KANDUS, P.; LACERDA, L. D.; BOZELLI, R. L.; ESTEVES, F. A.; NUNES DA CUNHA, C.; MALTCHIK, L.; SCHÖNGART, J.; SCHAEFFER-NOVELLI, Y.; AGOSTINHO, A. A. Brazilian wetlands: their definition, delineation, and classification for research, sustainable management, and protection. Aquatic Conservation: Marine and Freshwater Ecosystems, 24 (1), p. 5-22, 2014 a.

JUNK, W. J.; PIEDADE, M. T. F.; LOURIVAL, R.; WITTMANN, F.; KANDUS, P.; LACERDA, L. D.; BOZELLI, R. L.; ESTEVES, F. A.; NUNES DA CUNHA, C.; MALTCHIK, L.; SCHOENGART, J.; SCHAEFFER-NOVELli, Y.; AGOSTINHO, A. A.; NÓBREGA, R. L. B. Parte I: Definição e Classificação das Áreas Úmidas (AUs). Brasileiras: Base Cientifica para uma Nova Política de Proteção e Manejo Sustentável. In: NUNES DA CUNHA, C; PIEDADE, M. T. F.; JUNK, W. J. (Orgs.). Classificação e Delineamento das Áreas Úmidas Brasileiras e de seus Macrohabitats. Cuiabá-MT: EdUFMT, 2014b. p. 13-76.

NUNES DA CUNHA, C.; JUNK, W. J. Classificação dos Macrohabitats do Pantanal Mato-grossense. In: NUNES DA CUNHA, C; PIEDADE, M. T. F.; JUNK, W. J. (Orgs.). Classificação e Delineamento das Áreas Úmidas Brasileiras e de seus Macrohabitats. Cuiabá-MT: EdUFMT, 2014. p. 77-122.

NUNES DA CUNHA, C.; JUNK, W. J. O que e uma área úmida. In: NUNES DA CUNHA, C.; ARRUDA, E. C.; JUNK, W. J. Marcos referenciais para lei federal do Pantanal e gestão de outras áreas úmidas. Cuiabá: EdUFMT e Carlini \& Caniato, 2017. p. 17-21.

SEIDL, A.; MORAES, A. Global valuation of ecosystem services: application to the Pantanal da Nhecolandia, Brazil. Ecological Economics, 33 (1), p. 1-6, 2000. 